\title{
Genitourinary Symptoms in Breast Cancer Survivors: Prevalence, Correlates, and Relationship with Sexual Functioning
}

Ying Sheng, ${ }^{1} \mathrm{PhD}$, RN; Janet S. Carpenter, ${ }^{1} \mathrm{PhD}, \mathrm{RN}, \mathrm{FAAN}$; Andrea A. Cohee, ${ }^{1,2} \mathrm{PhD}, \mathrm{RN}$;

Susan Storey, ${ }^{1,2} \mathrm{PhD}, \mathrm{RN}$, AOCNS; Timothy E. Stump, ${ }^{3}$ MA; Patrick O. Monahan, ${ }^{3} \mathrm{PhD}$; David Cella, ${ }^{4} \mathrm{PhD}$; Victoria L. Champion, ${ }^{1,2} \mathrm{PhD}, \mathrm{RN}, \mathrm{FAAN}$

Ying Sheng, PhD, RN, ${ }^{1}$ is a Postdoctoral Research Fellow. Email: shengyin@iu.edu

Janet S. Carpenter, $\mathrm{PhD}, \mathrm{RN}, \mathrm{FAAN},{ }^{1}$ is a Distinguished Professor, Audrey Giesel Chair of Innovation, and Associate Dean of Research. Email: carpentj@iu.edu

Andrea A. Cohee, PhD, RN, ${ }^{1,2}$ is an Assistant Professor. Email: aamaners@iu.edu

Susan Storey, PhD, RN, AOCNS, ${ }^{1,2}$ is an Assistant Professor. Email: sustorey@iu.edu

Timothy E. Stump, MA, ${ }^{3}$ is a statistician.Email: tstump@iu.edu

Patrick O. Monahan, $\mathrm{PhD},{ }^{3}$ is a Professor, and Director of Statistics \& Psychometrics for Indiana

University Cancer Prevention \& Control Program. Email: pmonahan@iu.edu

David Cella, $\mathrm{PhD},{ }^{4}$ is a Ralph Seal Paffenbarger Professor, Chair of Department of Medical

Social Sciences, Director of Institute for Public Health and Medicine - Center for Patient-

Centered Outcomes. Email: d-cella@northwestern.edu

Victoria L. Champion, PhD, RN, FAAN, ${ }^{1,2}$ is a Distinguished Professor, Edward and Sarah Stam

Cullipher Endowed Chair, and Associate Director of Community Outreach and Population

Science. Email: vchampio@iu.edu

${ }^{1}$ Indiana University School of Nursing, Indianapolis, IN 46202, USA.

This is the author's manuscript of the work published in final edited form as:

Sheng, Y., Carpenter, J. S., Cohee, A. A., Storey, S., Stump, T. E., Monahan, P. O., Cella, D., \& Champion, V. L. (2021). Genitourinary Symptoms in Breast Cancer Survivors: Prevalence, Correlates, and Relationship with Sexual Functioning. Oncology Nursing Forum, 48(2), 229-241.

https://doi.org/10.1188/21.ONF.229-241 
${ }^{2}$ Indiana University Melvin and Bren Simon Comprehensive Cancer Center, Indianapolis, IN, 46202, USA.

${ }^{3}$ Department of Biostatistics, Indiana University School of Medicine, Indianapolis, IN 46202, USA.

${ }^{4}$ Department of Medical Social Sciences, Feinberg School of Medicine, Northwestern University, Chicago, IL, 60611, USA.

Correspondence concerning this article should be addressed to Ying Sheng, Indiana University School of Nursing, 600 Barnhill Dr. NU 317C, Indianapolis, IN 46202, USA. Email: shengyin@iu.edu

Authorship/contributors: Drs. Ying Sheng and Janet S. Carpenter developed the concept and design, performed statistical analysis, and prepared the manuscript. Drs. Andrea A. Cohee, Susan Storey, Patrick O. Monahan, and Mr. Timothy E. Stump provided statistical support and revised the manuscript. Dr. David Cella provided critical edit to the manuscript. Dr. Victoria L. Champion provided data, statistical support, and revised the manuscript.

Conflict of Interest Statement: Drs. Sheng, Cohee, Storey, Monahan, and Champion, and Mr. Stump have nothing to disclose. Dr. Carpenter reports personal fees from RoundGlass Inc., Astellas Pharma Inc., Kappa Santé, and Sojournix; and unpaid consulting with QUE oncology. Dr. Cella reports personal fees from Janssen Global Services as a consultant. He is also the president of FACIT.org. 


\begin{abstract}
Objectives: To 1) evaluate the prevalence of genitourinary symptoms; 2) explore which demographic and clinical factors predict genitourinary symptoms; and 3) evaluate the association between genitourinary symptoms and sexual functioning in breast cancer survivors.

Sample and Setting: A secondary analysis of cross-sectional patient-reported outcomes data from 1,085 breast cancer survivors age 18-45 years old or 55-70 years old when diagnosed with breast cancer.

Methods and Variables: Prevalence of genitourinary symptoms and correlations between symptoms and demographics, clinical factors, and sexual functioning were identified using descriptive analysis, chi-square tests, t-tests, multivariable logistic regression analysis, and Pearson correlation coefficients.
\end{abstract}

Results: Reported symptoms included: vaginal/vulvar irritation (15.0\%), pelvic discomfort $(14.9 \%)$, problems with urinary control $(9.1 \%)$, vaginal infection $(4.2 \%)$, and vaginal bleeding (4.1\%). About one-third (33.6\%) of participants reported $\geq 1$ symptom, and $10.1 \%$ reported $\geq 2$ genitourinary symptoms. Younger age, more comorbidities, and taking menopausal symptom treatments were significantly related to reporting genitourinary symptoms. More genitourinary symptoms and specific symptoms were associated with lower sexual functioning.

Implications for Nursing: The identified prevalence, correlates, and relationship of genitourinary symptoms with sexual functioning support the assessment and treatment of genitourinary symptoms as part of routine care for breast cancer survivors.

Keywords breast cancer; survivors; vaginal atrophy; vulvovaginal atrophy; urogenital symptoms; sexual functioning 


\section{Genitourinary Symptoms in Breast Cancer Survivors: Prevalence, Correlates, and Relationship with Sexual Functioning}

Up to $70 \%$ of postmenopausal women experience genitourinary symptoms (Gandhi et al., 2016; Moral et al., 2018; The North American Menopause Society, 2020). Although genitourinary symptoms are usually caused by naturally occurring postmenopausal estrogen loss, they also can be caused by chemotherapy and/or endocrine therapy for breast cancer (Mac Bride, Rhodes, \& Shuster, 2010; The North American Menopause Society, 2020). Breast cancer survivors suffer from genitourinary symptoms, yet they are under-reported (Baumgart et al., 2011), under-assessed, and under-treated (Biglia, Pup, Masetti, Villa, \& Nappi, 2020; Cook, Sutherland, Baum, Schover, \& Newman, 2018; Lester \& Bernhard, 2009; Moral et al., 2018). Genitourinary symptoms, also called genitourinary syndrome of menopause (Portman, Gass, \& on behalf of the Vulvovaginal Atrophy Terminology Consensus Conference Panel, 2014), are defined as unpleasant symptoms that include urologic and genital symptoms. Urologic symptoms indicate problems with urinary control, including stress/urge incontinence (Chung, Behrendt, Wong, Flores, \& Mortimer, 2020), urgency, frequency, dysuria or burning, recurrent urinary tract infections, and dryness (Cook et al., 2018). Genital symptoms include, but are not limited to, symptoms of vaginal dryness, vaginal/vulvar irritation, soreness and burning, itching, bleeding, infection, and vaginal/pelvic pain (Nappi \& Kokot-Kierepa, 2012; Portman et al., 2014). Genitourinary symptoms are associated with lower quality of life among breast cancer survivors (Gandhi et al., 2016; Lester \& Bernhard, 2009) and can interfere with sexual functioning (Gandhi et al., 2016).

A comprehensive assessment of genitourinary symptoms in breast cancer survivors has not been reported (Lester \& Bernhard, 2009). Most studies have focused on a single symptom or 
the most common symptoms, such as vaginal dryness, vaginal/vulva irritation, or problems with urinary control (The North American Menopause Society, 2020). In addition, the prevalence of genitourinary symptoms varies due to differences in symptom assessments. In prior studies of breast cancer survivors, $32 \%$ to $75 \%$ reported at least one genitourinary symptom such as vaginal discharge, irritation, bleeding, dryness, and urine control problems (Baumgart et al., 2011; Biglia et al., 2020; Chin et al., 2009; Lester, Bernhard, \& Ryan-Wenger, 2012). Many of these studies with selected samples suggested the need for a large sample estimate in a group of women unselected for symptoms of any kind.

While cancer treatments are known to increase the risk of genitourinary symptoms in breast cancer survivors (The North American Menopause Society, 2020), little is known about which demographic and clinical factors are related to genitourinary symptoms in breast cancer survivors. In cancer survivors with diagnoses other than breast cancer, factors influencing symptom burden include age, number of comorbidities, income, cancer site (Bubis et al., 2018), education, and ongoing cancer treatment (Shi et al., 2011). In women without cancer, factors associated with symptoms include body mass index (BMI) (Geng, Zheng, Zhou, Li, \& Tao, 2018), menopause, ovarian failure, and vaginal childbirth (Gandhi et al., 2016). Because demographic and clinical factors related to genitourinary symptoms in breast cancer survivors have not been well studied, additional research exploring their relationship is needed in order to better manage survivors' symptoms.

Sexual functioning has been reported as a significant problem in breast cancer survivors, and genitourinary symptoms have been linked with sexual functioning (Champion et al., 2014). In breast cancer survivors, some studies have shown that genitourinary symptoms were associated with lower quality of sexual life (Gandhi et al., 2016; Lester \& Bernhard, 2009; Moral 
et al., 2018; Shifren et al., 2019) due to decreases in sexual lubrication, and loss of or difficulties with libido, sexual arousal, orgasm, pleasure from sex, and sexual desire (Boquiren et al., 2016; Gupta et al., 2006). The correlation between genitourinary symptoms and sexual functioning varies based on the number and type of symptoms assessed. Nevertheless, to date, information regarding the association between genitourinary symptoms and sexual functioning in breast cancer survivors is still limited. With hesitancy in talking about sexual functioning, both genitourinary symptoms and sexual functioning are often under-assessed (Mac Bride et al., 2010).

The purpose of this study was to understand better the prevalence of genitourinary symptoms, factors related to those symptoms, and the relationship with sexual functioning in breast cancer survivors. Specifically, study aims were to 1) evaluate the prevalence of genitourinary symptoms (vaginal/vulvar irritation, pelvic discomfort, problems with urinary control, vaginal infection, and vaginal bleeding), 2) explore which demographic and clinical factors predict genitourinary symptoms, and 3) evaluate the association between genitourinary symptoms and sexual functioning in breast cancer survivors.

\section{Conceptual Model}

The theory of unpleasant symptoms illustrates reciprocal interactions among three main components: influential factors, symptoms, and performance outcomes (Lenz \& Pugh, 2003; Lenz, Pugh, Milligan, Gift, \& Suppe, 1997). According to this theory, influential factors (e.g., physiological, psychological, and situational) can affect the intensity, timing, level of perceived distress, and quality of symptoms, which, in turn, affect performance outcome (e.g., functional, cognitive activities, and physical). The symptoms also interact with each other. While physiological, psychological, and situational factors influence symptoms and performance, 
symptoms and performance also provide feedback to these physiological, psychological, and situational factors. For example, depression (e.g., psychological factor) affects pain experience (e.g., symptom), the intensity of pain influences the treatment of depression, both depression and pain impair the ability to work (e.g., performance outcome). Conversely, the intensity of pain and the inability to work affect depression management (Bair, Robinson, Katon, \& Kroenke, 2003).

Based on the theory of unpleasant symptoms, we developed a Situation Specific Model of Genitourinary Symptoms in Breast Cancer Survivors (Figure 1). Given the limitations of the dataset used for this study, psychological factors and the intensity, timing, perceived distress level, and quality of symptoms were removed from the model. With this revised model, two types of factors were relevant to this report. The first type of factor was physiological, which included estrogen deprivation due to chemotherapy and/or endocrine therapy such as selective estrogen receptor modulators (SERM; e.g., tamoxifen) or aromatase inhibitors (AI; e.g., letrozole). The genitourinary tract (vulva, vagina, lower urinary tract) and supported pelvic structure contain epithelial tissue that is sensitive to estrogen deprivation (The North American Menopause Society, 2020). Estrogen deprivation results in a thinner vaginal and urethral epithelium, loss of fat, narrow vaginal opening, and shrinkage of the urethra and clitoral prepuce. This, in turn, can lead to atrophy in the vulva, vagina, pelvic floor, and urinary tract that results in a variety of genitourinary symptoms, including vaginal soreness and bleeding, vaginal dryness, infection, itching and irritation, discomfort, urinary incontinence, and difficult or painful intercourse (Chin et al., 2009; Lester, Pahouja, Andersen, \& Lustberg, 2015). The second type of factor was situational, which included demographic and clinical factors such as age, marital status, education, race and ethnicity, income, BMI, age at first menses, years post-breast cancer 
diagnosis, non-breast cancer comorbidities, current menopausal status, whether women were using treatment to alleviate genitourinary symptoms (e.g., menopausal treatments), and use of endocrine therapy. The performance outcome was sexual functioning. Sexual functioning is defined as how the body responds to sexual stimulation that is expressed by sexual activity, desire, lubrication, orgasm, frequency, satisfaction, and pain (Rosen et al., 2000). Lastly, the symptom variable in the model was genitourinary. Genitourinary symptoms can negatively impact sexual interest, lubrication, arousal, orgasm during sexual activity, and sexual satisfaction. Thus, genitourinary symptoms can be related to decreased sexual functioning (Burich \& DeGregorio, 2011; Melisko, Goldman, \& Rugo, 2010; Nappi, Kingsberg, Maamari, \& Simon, 2013).

\section{Methods}

This is a secondary analysis of data from a large cohort study about the quality of life in younger versus older breast cancer survivors. The parent study collected data from younger $(\mathrm{n}=$ $505)$ and older $(n=622)$ breast cancer survivors, partners, and acquaintance controls of women without breast cancer. The eligibility criteria for breast cancer survivors are reported elsewhere (Champion et al., 2014). Briefly, women were recruited who were treated for breast cancer and diagnosed either when they were 45 years or younger or when they were 55-70 years of age. They had completed breast cancer treatment trials from the Eastern Cooperative Oncology Group - American College of Radiation Imaging Network (ECOG-ACRIN) and were identified from the ECOG-ACRIN statistical center database. Eligibility included not having a recurrence, being 3 to 8 years post-diagnosis, and treated with a similar chemotherapy regimen of adriamycin, paclitaxel, and cyclophosphamide. Informed consent was obtained (Champion et al., 2014). 
Because the goal of this analysis was to assess a host of genitourinary symptoms and test associated variables rather than test age group differences, the younger and older groups were combined. Only breast cancer survivors with complete data on the genitourinary symptoms were included in this analysis. The parent study contained 1,127 breast cancer survivors. We identified $1,085(96.3 \%)$ survivors who had data for all five genitourinary symptoms (i.e., vaginal/vulvar irritation, pelvic discomfort, problems with urinary control, vaginal infection, and vaginal bleeding). Thus, for this secondary analysis, a total of 1,085 breast cancer survivors (493 younger and 592 older) were included, with ages ranging from 28-78 years.

\section{Measures}

Influential factors were selected based on the concept model (Figure 1). The dataset contained demographic and clinical factors that had been collected using an investigator designed questionnaire and medical record reviews. Demographic information included age, marital status, education, race, ethnicity, income, and BMI. Clinical factors included age at first menses, years post-breast cancer diagnosis, number of reported non-breast cancer comorbidities (e.g., heart disease, hypertension, diabetes, and depression), current menopausal status, taking treatment for menopausal symptoms (i.e., vitamin E, herbs, vaginal creams/lubricants, vaginal estrogen, antidepressants, and other), and current use of endocrine therapy (SERM: tamoxifen, raloxifene, or toremifene, or AI: letrozole, anastrozole, or exemestane). Current menopausal status was measured by asking if women "had a menstrual period in the last 3 months, no change in regularity" (premenopausal), "had a menstrual period in the last 3 months, but cycles are less regular" or "had a menstrual period in the last 12 months, but not in the last 3 months" (perimenopausal), or "have not had a menstrual period in the last 12 months" (postmenopausal). Reasons for postmenopausal status included natural aging (naturally), hysterectomy or ovaries 
removed (surgically), breast cancer treatment, medicine not related to breast cancer, or other or unsure (artificially, menopause due to ovarian failure secondary to drugs, radiation or chemicals, medications (Geerlings et al., 2001)).

The dataset contained self-reported genitourinary symptoms. Women were asked if they had ever been diagnosed with or had a "problem with urinary control." Response options were “yes" or "no." Pelvic and vaginal symptoms were assessed as "have had pelvic discomfort," "have had vaginal bleeding (between periods)," "have had a vaginal infection," and "have had vaginal/vulvar irritation" in the past month. For these symptoms, there were five response options from "not at all (1)" to "very much (5)." Responses of "not at all" were considered "no symptom," and the remaining responses were collapsed into "yes symptom." In this way, all genitourinary symptoms could be consistently reported to match the dichotomous response option for "problem with urinary control."

The dataset also contained self-reported sexual functioning, which was assessed using a 7-item Sexual Index Scale whose items were summed to create a total score and two subscale scores (sexual enjoyment and sexual difficulty). Response options ranged from 1 (strongly agree) to 5 (strongly disagree). After reverse scoring relevant items, total scores ranged from 7 to 35 (higher scores indicating better functioning), enjoyment scores ranged from 4 to 20 (higher score indicating more enjoyment), and sexual difficulty ranged from 3 to 15 (higher score indicating more difficulty). Interest, enjoyment, satisfaction, and thoughts of sexual activity composed the sexual enjoyment items (e.g., "I am able to relax and enjoy sexual activity"). Problems with becoming aroused, lubricated, and orgasm during sexual activity composed the sexual difficulty items (e.g., "I have difficulty becoming sexually aroused"). This scale was a modified version of 
an existing scale (Hudson, Harrison, \& Crosscup, 1981) with a Cronbach's alpha of 0.79 (Champion et al., 2013).

\section{Statistical Analysis}

Statistical analysis was performed using IBM SPSS statistics, version 26.0. For Aim 1, descriptive statistics were used to generate the percentage of women with each of the five genitourinary symptoms (yes, no). For Aim 2, demographic and clinical factors were reported as mean (standard deviation) for continuous variables or number (percentage) for categorical variables. Chi-square tests and t-tests were used to compare these factors between asymptomatic (no symptoms) and symptomatic (at least one symptom reported) women. Chi-square and t-tests were not performed for individual symptoms (yes, no) because several symptoms were not frequently reported. All factors that were significant at $\mathrm{p} \leq .20$ were entered into a multivariable logistic regression model (Hosmer, Lemeshow, \& Sturdivant, 2013). Having at least one genitourinary symptom (yes, no) was the dichotomous dependent variable. The correlates were age, marital status, non-breast cancer comorbidity, race, menopausal status, and taking treatment for menopausal symptoms. For Aim 3, t-tests were used to compare sexual functioning, sexual enjoyment, and sexual difficulty between the presence and absence of individual symptoms as well as between asymptomatic (no symptoms) and symptomatic women (at least one symptom; two or more symptoms). Pearson correlation coefficients were reported to assess the relationship between the number of genitourinary symptoms and sexual functioning variables.

\section{Results}

The sample demographic and clinical variables for symptomatic versus asymptomatic survivors are shown in Table 1. The results indicated several significant findings. The average age of symptomatic survivors at the time of the study was slightly younger than 55 years old, 
while the asymptomatic survivors were an average age of 58 years old $(p=.010)$. Symptomatic survivors reported slightly more comorbidities (2.2) than asymptomatic survivors (1.9) $(p=$ .024). More symptomatic survivors were pre- or perimenopausal $(\mathrm{p}<.001)$ and took treatments for their menopausal symptoms $(\mathrm{p}<.001)$ than asymptomatic survivors. The entire sample was primarily married or in a long-term committed relationship (79.3\% in symptomatic survivors and $73.3 \%$ in asymptomatic survivors). The majority of the entire sample had at least a 2 -year college education, was non-Hispanic and Caucasian, had incomes over $\$ 30,000$ at the time of the study, and were overweight or obese. For the whole sample, the average age of first menses was approximately 12 years, and the average time since the initial breast cancer diagnosis was almost 6 years. At the time of the study, the entire sample had an average of 2 non-breast cancer comorbidities. The majority of the sample was postmenopausal (naturally, surgically, or artificially), and slightly less than half reported taking a SERM or AI at the time of the study.

\section{Aim 1: Symptom Prevalence}

Prevalence rates of the five symptoms for the sample are reported in Table 2. The most common symptom was vaginal/vulvar irritation (15.0\%), followed by pelvic discomfort (14.9\%), problems with urinary control $(9.1 \%)$, vaginal infection $(4.2 \%)$, and vaginal bleeding $(4.1 \%)$. Slightly more than one-third $(33.6 \%)$ of the sample had at least one genitourinary symptom, and $10.1 \%$ had two or more symptoms. Only $1(<1 \%)$ breast cancer survivor reported having all five symptoms.

\section{Aim 2: Demographic and Clinical Factors and Symptoms}

The bivariate analyses of demographic and clinical factors included 365 symptomatic and 720 asymptomatic survivors (see Table 1). The analyses showed that breast cancer survivors with at least one genitourinary symptom were more likely to be younger, married, and minority 
race (i.e., Black or African American, Native Hawaiian or other Pacific Islander, Asian, American Indian or Alaskan Native, or Other). They also had a greater number of non-breast cancer comorbidities, were pre- or perimenopausal, and were taking treatments for menopausal symptoms (all $\mathrm{p} \leq .20)$. There was no difference between asymptomatic and symptomatic women on education, Hispanic / Latina, income, BMI, age at first menses, years post-breast cancer diagnosis, and whether currently taking SERM or AI (all $p>.05)$.

The logistic regression model showed that having at least one genitourinary symptom was associated with being younger (odds ratio $[\mathrm{OR}]=0.98,95 \%$ confidence interval $[\mathrm{CI}][0.96$, 0.99], $\mathrm{p}=.010)$, a greater number of non-breast cancer comorbidities (OR $=1.19,95 \% \mathrm{CI}[1.09$, 1.29], $\mathrm{p}<.001)$, and taking treatment for menopausal symptoms $(\mathrm{OR}=1.73,95 \% \mathrm{CI}[1.31$, 2.30], $\mathrm{p}<.001$ ) (see Table 3). In addition, compared to premenopausal women, those who were artificially postmenopausal (due to breast cancer treatment and other or unsure) were less likely to report genitourinary symptoms $(\mathrm{OR}=0.50,95 \% \mathrm{CI}[0.28,0.89], \mathrm{p}=.018)$.

\section{Aim 3: Genitourinary Symptoms and Sexual Functioning}

Women reporting one or two or more symptoms were associated with lower sexual functioning, characterized by less sexual enjoyment and more sexual difficulty (Table 4; all p < .001). Specific symptoms also were associated with lower sexual functioning, with a few exceptions. Vaginal bleeding was not associated with any aspect of sexual functioning, pelvic discomfort was not associated with sexual difficulty, and vaginal infection was only marginally $(p=.096)$ associated with sexual enjoyment. The total number of genitourinary symptoms was weakly correlated with sexual functioning total scores, and sexual enjoyment and sexual difficulty subscales at $-.16,-.15$, and .15 (all $\mathrm{p}<.001$ ), respectively.

\section{Discussion}


To our knowledge, this is the first study to evaluate the prevalence of multiple genitourinary symptoms, the relationship of these symptoms with demographic and clinical factors, and the relationship with sexual functioning in a large cohort of long-term breast cancer survivors. Our findings add to the literature on the prevalence of genitourinary symptoms in long-term breast cancer survivors. Unlike previous studies that examined single symptoms or selected participants based on symptoms, our data included five genitourinary symptoms (i.e., vaginal/vulvar irritation, pelvic discomfort, problems with urinary control, vaginal infection, and vaginal bleeding).

Regarding prevalence, our finding that $33.6 \%$ of breast cancer survivors reported at least one of the five genitourinary symptoms is lower than other previously published studies that found 50\% to 75\% prevalence rates (Baumgart et al., 2011; Chin et al., 2009; Sousa et al., 2018). For example, Baumgart et al. (2011) found that about 58\% of postmenopausal breast cancer survivors with AI treatment and $32 \%$ of those on tamoxifen treatment had at least one of eight genitourinary or menopausal symptoms, including vaginal bleeding, vaginal discharge, vaginal irritation, vaginal dryness, dyspareunia, hot flashes, cold sweats, and night sweats. Plausible explanations for variations in prevalence include differences in menopausal status, cancer-related endocrine therapy, and the number and types of genitourinary or menopausal symptoms assessed. The present study included breast cancer survivors of pre-, peri- and postmenopausal status, with most being postmenopausal and less than half (symptomatic, 44.4\%; asymptomatic, 45.8\%) using SERM or AI. The previous studies included only breast cancer survivors who were postmenopausal (Baumgart et al., 2011; Chin et al., 2009) or taking adjuvant endocrine therapy (Sousa et al., 2018). The possible reason for the lower prevalence could be that the women in our 
study were not selected based on having genitourinary symptoms or taking treatment for these symptoms.

Consistent with our Situation Specific Model of Genitourinary Symptoms in Breast Cancer Survivors (Figure 1), we found correlations between the demographic and clinical factors and the genitourinary symptoms. Findings that demographic and clinical factors predicted genitourinary symptoms provide some evidence of who is more likely to report symptoms. In our study, symptomatic survivors were younger. The parent study found that younger survivors reported worse anxiety, marital satisfaction, and fear of recurrence than older survivors (Champion et al., 2014). There is some support for the idea that these younger survivors were more aware of genitourinary symptoms. For example, trouble having children and loss of fertility due to premature menopause may make younger survivors more likely to report genitourinary symptoms (Ben Charif et al., 2015; Su et al., 2020). In addition, although Bubis and colleagues (2018) did not specifically study breast cancer survivors and genitourinary symptoms, they found that, based upon Cancer Care Ontario’s Symptom Management Reporting Database, younger age was a predictor for symptom burden for survivors (Bubis et al., 2018). They reported that among 120,745 participants, cancer (e.g., breast [30.0\% of the total survivors], gastrointestinal, or genitourinary) survivors younger than 50 years old were more likely to report ongoing symptoms (e.g., pain, anxiety, or tiredness) than survivors 51 to 60 years old. Our study also found that those with greater non-breast cancer-related comorbidities were more likely to be symptomatic, which is consistent with previous studies (Constantine et al., 2014; Moyneur et al., 2020). Other studies also found that survivors are more likely to report symptoms such as pain, anxiety, or urine control problems as comorbidities increase (Bubis et al., 2018; Shi et al., 2011). Our finding regarding menopausal status is counterintuitive. We found that artificially 
postmenopausal women were less likely to be symptomatic than premenopausal women, independent of their current age. Other studies showed that being postmenopausal was a main risk factor for genitourinary symptoms (Gandhi et al., 2016; Geng et al., 2018), and a systematic review showed that $50 \%$ of postmenopausal women reported genitourinary symptoms (Parish et al., 2013). It is possible that premenopausal women were more sexually active, younger, and more aware of the genitourinary symptoms. In addition, our study found that survivors taking treatment for menopausal symptoms were more likely to report genitourinary symptoms. Genitourinary symptoms are considered a subset of menopausal symptoms (Calleja-Agius \& Brincat, 2015; Moral et al., 2018); thus, it is logical that women who were symptomatic enough to take treatments for other menopausal symptoms would also report more genitourinary symptoms.

Although other studies have shown that education, BMI, and currently taking SERM or AI were related to genitourinary symptoms, our findings were not consistent. Aydin and colleagues (Aydin, Hassa, Oge, Yalcin, \& Mutlu, 2014) found that lower education status and high BMI were negatively associated with genitourinary symptoms in a study of 1,071 breast cancer survivors with an average age of 50.4 (SD 4.7) years. Geng et al. (2018) also found that BMI was negatively associated with genitourinary symptoms in a study of 1,294 women, including 607 premenopausal and 687 postmenopausal, age 52.0 (4.8) years on average. Although we found no significant difference in having genitourinary symptoms between those who did versus did not use SERM or AI, over $44.4 \%$ of SERM- or AI-treated breast cancer survivors in the present study experienced at least one genitourinary symptom. This finding is consistent with the genitourinary symptom rates of 58\% among AI-treated and $32 \%$ among tamoxifen-treated breast cancer survivors reported by Baumgart et al. (2011). 
As depicted by our model (Figure 1), symptoms and sexual functioning were related. Findings of the relationship between genitourinary symptoms and sexual functioning were weak but consistent with previous studies (Baumgart, Nilsson, Evers, Kallak, \& Sundström-Poromaa, 2013; Biglia et al., 2017; Boquiren et al., 2016; Gupta et al., 2006; Lester \& Bernhard, 2009; Sousa, Peate, Jarvis, Hickey, \& Friedlander, 2017; Sousa et al., 2018). Except for vaginal bleeding, each symptom was associated with either lower total sexual functioning scores, less sexual enjoyment, more sexual difficulty, or all three of the sexual functioning variables. However, the magnitude of the correlations was weak between the number of genitourinary symptoms and sexual functioning, sexual enjoyment, and sexual difficulty. These weak correlations may be due to three situations. First, correlations may have differed because of differences in symptoms across studies. For example, our dataset did not include vaginal dryness, which has a higher association with sexual problems compared to other genitourinary symptoms (Gupta et al., 2006; Lester et al., 2012). Gupta et al. (2006) found that vaginal dryness and sexual problems were more highly correlated compared to other symptoms $(\mathrm{r}=.58)$. In addition, Boquiren and colleagues (2016) found that vaginal dryness predicted sexual functioning (beta coefficient $=-0.50)$. Second, the weak correlation may be due to differences in sexual functioning measures. Using a Likert-type 5-point (0-4) scale, Gupta and colleagues (2006) found that $60 \%$ of breast cancer survivors reported sexual problems. Additionally, Boquiren et al. (2016) reported that $82.5 \%$ of breast cancer survivors with body image disturbance reported sexual dysfunction when measured using the Female Sex Function Index. Unlike previous studies (Baumgart et al., 2013; Biglia et al., 2017; Lester et al., 2012), this study did not measure pain with intercourse. Third, weak correlations may be due to different populations. The present study included both younger and older breast cancer survivors. In other studies, younger 
survivors had higher rates of sexual dysfunction (Bober \& Varela, 2012). Older survivors, who may not be as sexually active, may not be as concerned with sexual functioning as a part of their quality of life. Future studies should include a more comprehensive list of genitourinary symptoms and all dimensional aspects of sexual functioning.

There were several strengths in this study. This study included a large dataset of breast cancer survivors with a wide age range of 28 to 78 years at the time of the study. This study included five genitourinary symptoms, all of which are part of the genitourinary syndrome of menopause. This study observed potential demographic and clinical factors related to genitourinary symptoms, which is another strength. In addition, this study tested the association of five individual symptoms with sexual functioning, sexual enjoyment, and sexual difficulty.

Some limitations need to be acknowledged. The cross-sectional study design limits the ability to explore a temporal relationship between genitourinary symptoms and demographic and clinical factors. This was a secondary data analysis, which limited the data available for this study. As a result, we could not study the full model of the theory of unpleasant symptoms. This study used a sexual survey measure that was modified from another scale (Hudson et al., 1981) and did not include the severity of sexual problems. The majority of participants were married, well educated, non-Hispanic and Caucasian, of relatively high income, and postmenopausal; thus, the findings may not be generalizable to other breast cancer survivors. An international survey found that more women in Finland reported that genitourinary symptoms impacted their quality of life and social life compared to women in other counties (e.g., USA, Sweden, and Canada) (Nappi \& Kokot-Kierepa, 2010). In addition, research has suggested that Hispanic women are more likely to discuss genitourinary symptoms with healthcare providers than women from other ethnic groups (Kingsberg, Wysocki, Magnus, \& Krychman, 2013). Given these 
findings of racial and ethnic differences, future studies of diverse racial and ethnic groups are needed.

\section{Implications for Practice}

Genitourinary symptoms are common in breast cancer survivors, impacting their survivorship care (Gandhi et al., 2016; Moral et al., 2018). Our findings have two important implications. First, understanding the association of genitourinary symptoms and demographic and clinical factors may help nurses identify and refer survivors who are at high risk. Given the prevalence of genitourinary symptoms, screening and assessing symptoms should be a part of routine care for breast cancer survivors. Considering the stigma associated with talking about these symptoms, communication between healthcare providers and survivors will be critical for early identification of symptoms.

Second, understanding factors related to symptoms will help clinicians and researchers develop targeted treatments for survivors at risk of experiencing symptoms. If genitourinary symptoms can be prevented and treated with early assessment and appropriate treatment (Sousa et al., 2017; Vincent, 2015), sexual functioning may improve (Gandhi et al., 2016). Vaginal estrogen treatment is contraindicated, though findings from a meta-analysis suggested low-dose vaginal estrogen was a safe and effective treatment (Pavlović et al., 2019). Women with earlystage breast cancer had improved genitourinary symptoms and sexual functioning after receiving $7.5 \mu \mathrm{g}$ of estradiol every 24 hours for 90 days (Melisko et al., 2017). Other treatments, such as vaginal dehydroepiandrosterone and laser therapy, should be used with caution due to insufficient evidence of their safety and efficacy for breast cancer survivors (The North American Menopause Society, 2020). Vaginal moisturizers and lubricants (nonhormone therapies) are available without a prescription, which may help alleviate genitourinary symptoms 
in breast cancer survivors (Crean-Tate, Faubion, Pederson, Vencill, \& Batur, 2020; Gandhi et al., 2016; Sussman, Kruse, Thacker, \& Abraham, 2019; The North American Menopause Society, 2020).

Nurses play a vital role in educating survivors and encouraging communication with oncologists about genitourinary symptoms, sexual functioning, and treatment choices. Early assessment, appropriate treatments, and communication between survivors and healthcare providers are important for reducing symptoms, improving sexual functioning, and enhancing survivors' quality of life (Gandhi et al., 2016).

\section{Conclusion}

This study identified the prevalence, correlates, and relationship to sexual functioning of five genitourinary symptoms in breast cancer survivors. The relationship between these symptoms and demographic and clinical factors provides preliminary information regarding who may be at higher risk for symptoms. Results from this study may lead to developing targeted interventions for genitourinary symptoms, which may improve sexual functioning. 


\section{Knowledge Translation:}

- Genitourinary symptoms were common among breast cancer survivors and should be assessed and treated during routine oncology clinical visits.

- Demographic and clinical factors can be used to identify breast cancer survivors who are at higher risk for genitourinary symptoms and inform referrals and treatments for those who are more likely to experience genitourinary symptoms.

- Genitourinary symptoms are negatively associated with sexual functioning.

\section{Acknowledgements:}

Dr. Sheng is supported as a postdoctoral fellow under 5T32CA117865 (V. Champion, PI). The data in this manuscript came from a study that was coordinated by the ECOG-ACRIN Cancer Research Group (Robert L. Comis, MD and Mitchell D. Schnall, MD, PhD, Group CoChairs) and supported in part by Public Health Service Grants CA189828, CA180795, CA37403, CA35199, CA17145 and CA49883, and from the National Cancer Institute, National Institutes of Health and the Department of Health and Human Services. Dr. Cohee is supported by Indiana Clinical and Translational Sciences Institute (KL2 Program), UL1TR002529 (A Shekhar, PI). Dr. Storey is supported by an RE01 from the Oncology Nursing Foundation. The manuscript content is solely the responsibility of the authors and does not necessarily represent the official views of the National Institutes of Health. 


\section{References}

Aydin, Y., Hassa, H., Oge, T., Yalcin, O. T., \& Mutlu, F. Y. (2014). Frequency and determinants of urogenital symptoms in postmenopausal Islamic women. Menopause, 21(2), 182-187. https://doi.org/10.1097/GME.0b013e3182937966

Bair, M. J., Robinson, R. L., Katon, W., \& Kroenke, K. (2003). Depression and pain comorbidity: A literature review. Archives of Internal Medicine, 163(20), 2433-2445. http://doi.org/10.1001/archinte.163.20.2433

Baumgart, J., Nilsson, K., Evers, A. S., Kallak, T. K., \& Sundström-Poromaa, I. (2013). Sexual dysfunction in women on adjuvant endocrine therapy after breast cancer. Menopause, 20(2), 162-168. https://doi.org/10.1097/gme.0b013e31826560da

Baumgart, J., Nilsson, K., Stavreus-Evers, A., Kask, K., Villman, K., Lindman, H., . . . Sundström-Poromaa, I. (2011). Urogenital disorders in women with adjuvant endocrine therapy after early breast cancer. American Journal of Obstetrics \& Gynecology, 204(1), 26.e21-27. https://doi.org/10.1016/j.ajog.2010.08.035

Ben Charif, A., Bouhnik, A.-D., Rey, D., Provansal, M., Courbiere, B., Spire, B., \& Mancini, J. (2015). Satisfaction with fertility- and sexuality-related information in young women with breast cancer-ELIPPSE40 cohort. BMC Cancer, 15(527). http://doi.org/10.1186/s12885-015-1542-0

Biglia, N., Bounous, V. E., D’Alonzo, M., Ottino, L., Tuninetti, V., Robba, E., \& Perrone, T. (2017). Vaginal atrophy in breast cancer survivors: Attitude and approaches among oncologists. Clinical Breast Cancer, 17(8), 611-617. https://doi.org/10.1016/j.clbc.2017.05.008. 
Biglia, N., Pup, L. D., Masetti, R., Villa, P., \& Nappi, R. E. (2020). Vulvovaginal atrophy (VVA) in breast cancer survivors (BCS) is still an unmet medical need: Results of an Italian Delphi Panel. Supportive Care in Cancer volume, 28, 2507-2512. https://doi.org/10.1007/s00520-019-05272-4

Bober, S. L., \& Varela, V. S. (2012). Sexuality in adult cancer survivors: Challenges and intervention. Journal of Clinical Oncology, 30(30), 3712-3719. https://doi.org/10.1200/JCO.2012.41.7915

Boquiren, V. M., Esplen, M. J., Wong, J., Toner, B., Warner, E., \& Malik, N. (2016). Sexual functioning in breast cancer survivors experiencing body image disturbance. PsychoOncology, 25, 66-76. http://doi.org/10.1002/pon.3819

Bubis, L. D., Davis, L., Mahar, A., Barbera, L., Li, Q., Moody, L., . . Coburn, N. G. (2018). Symptom burden in the first year after cancer diagnosis: An analysis of patient-reported outcomes. Journal of Clinical Oncology, 36(11), 1103-1110. https://doi.org/10.1200/JCO.2017.76.0876

Burich, R., \& DeGregorio, M. (2011). Current treatment options for vulvovaginal atrophy. Expert Review of Obstetrics \& Gynecology, 6(2), 141-151. https://doi.org/10.1586/eog.11.3

Calleja-Agius, J., \& Brincat, M. P. (2015). The urogenital system and the menopause. Climacteric, 18(1), 18-22. https://doi.org/10.3109/13697137.2015.1078206

Champion, V. L., Wagner, L. I., Monahan, P. O., Daggy, J., Smith, L., Cohee, A., . . Sledge Jr, G. W. (2014). Comparison of younger and older breast cancer survivors and age-matched controls on specific and overall QoL domains. Cancer, 120(15), 2237-2246. https://doi.org/10.1002/cncr.28737 
Champion, V. L., Ziner, K. W., Monahan, P. O., Stump, T. E., Cella, D., Smith, L. G., . . .

Sledge, G. W. (2013). Development and psychometric testing of a breast cancer survivor self-efficacy scale. Oncology Nursing Forum, 40(6), E403-410.

https://doi.org/10.1188/13.ONF.E403-E410

Chin, S. N., Trinkaus, M., Simmons, C., Flynn, C., Dranitsaris, G., Bolivar, R., \& Clemons, M. (2009). Prevalence and severity of urogenital symptoms in postmenopausal women receiving endocrine therapy for breast cancer. Clinical Breast Cancer, 9(2), 108-117. https://doi.org/10.3816/CBC.2009.n.020

Chung, C. P., Behrendt, C., Wong, L., Flores, S., \& Mortimer, J. E. (2020). Serial assessment of urinary incontinence in breast cancer survivors undergoing (Neo) adjuvant therapy. Journal of the National Comprehensive Cancer Network, 18(6), 712-716. https://doi.org/10.6004/jnccn.2020.7535

Constantine, G. D., Bruyniks, N., Princic, N., Huse, D., Palmer, L., Lenhart, G., . . Nappi, R. E. (2014). Incidence of genitourinary conditions in women with a diagnosis of vulvar/vaginal atrophy. Current Medical Research and Opinion, 30(1), 143-148. https://doi.org/10.1185/03007995.2013.850068

Cook, E. D., Sutherland, E. I., Baum, G. P., Schover, L. R., \& Newman, L. L. (2018). Missing documentation in breast cancer survivors: Genitourinary syndrome of menopause. Menopause, 24(12), 1360-1364. https://doi.org/10.1097/GME.0000000000000926

Crean-Tate, K. K., Faubion, S. S., Pederson, H. J., Vencill, J. A., \& Batur, P. (2020). Management of genitourinary syndrome of menopause in female cancer patients: A focus on vaginal hormonal therapy. American Journal of Obstetrics \& Gynecology, 222(2), 103-113. https://doi.org/10.1016/j.ajog.2019.08.043 
Gandhi, J., Chen, A., Dagur, G., Suh, Y., Smith, N., Cali, B., \& Khan, S. A. (2016).

Genitourinary syndrome of menopause: An overview of clinical manifestations, pathophysiology, etiology, evaluation, and management. American Journal of Obstetrics \& Gynecology, 215(6), 704-711. https://doi.org/10.1016/j.ajog.2016.07.045

Geerlings, M. I., Ruitenberg, A., Witteman, J. C., van Swieten, J. C., Hofman, A., van Duijn, C. M., . . Launer, L. J. (2001). Reproductive period and risk of dementia in postmenopausal women. The Journal of the American Medical Association, 285(11), 1475-1481. http://doi.org/10.1001/jama.285.11.1475

Geng, L., Zheng, Y., Zhou, Y., Li, C., \& Tao, M. (2018). The prevalence and determinants of genitourinary syndrome of menopause in Chinese mid-life women: A single-center study. Climacteric, 21(5), 478-482. https://doi.org/10.1080/13697137.2018.1458832

Gupta, P., Sturdee, D. W., Palin, S. L., Majumder, K., Fear, R., Marshall, T., \& Paterson, I. (2006). Menopausal symptoms in women treated for breast cancer: The prevalence and severity of symptoms and their perceived effects on quality of life. Climacteric, 9(1), 4958. https://doi.org/10.1080/13697130500487224

Hosmer, D. W., Lemeshow, S., \& Sturdivant, R. X. (2013). Applied logistic regression (3rd ed.). New Jersey: Hoboken.

Hudson, W. W., Harrison, D. F., \& Crosscup, P. C. (1981). A short-form scale to measure sexual discord in dyadic relationships. Journal of Sex Research, 17(2), 157-174. https://doi.org/10.1080/00224498109551110

Kingsberg, S. A., Wysocki, S., Magnus, L., \& Krychman, M. L. (2013). Vulvar and vaginal atrophy in postmenopausal women: Findings from the REVIVE (REal Women's VIews 
of Treatment Options for Menopausal Vaginal ChangEs) survey. The Journal of Sexual Medicine, 10(7), 1790-1799. http://doi.org/10.1111/jsm.12190

Lenz, E. R., \& Pugh, L. C. (2003). The theory of unpleasant symptoms. In M. J. Smith \& P. R. Liehr (Eds.), Middle range theory for nursing (pp. 165-195). New York: Springer.

Lenz, E. R., Pugh, L. C., Milligan, R. A., Gift, A., \& Suppe, F. (1997). The middle-range theory of unpleasant symptoms: An update. Advances in Nursing Science, 19(3), 14-27. https://doi.org/10.1097/00012272-199703000-00003

Lester, J. L., Bernhard, L., \& Ryan-Wenger, N. (2012). A self-report instrument that describes urogenital atrophy symptoms in breast cancer survivors. Western Journal of Nursing Research, 34(1), 72-96. https://doi.org/10.1177/0193945910391483

Lester, J. L., \& Bernhard, L. A. (2009). Urogenital atrophy in breast cancer survivors. Oncology Nursing Forum, 36(6), 693-398. https://doi.org/10.1188/09.ONF.693-698

Lester, J. L., Pahouja, G., Andersen, B., \& Lustberg, M. (2015). Atrophic vaginitis in breast cancer survivors: A difficult survivorship issue. Journal of Personalized Medicine, 5(2), 50-66. https://doi.org/10.3390/jpm5020050

Mac Bride, M. B., Rhodes, D. J., \& Shuster, L. T. (2010). Vulvovaginal atrophy. Mayo Clinic Proceedings, 85(1), 87-94. https://doi.org/10.4065/mcp.2009.0413

Melisko, M. E., Goldman, M., \& Rugo, H. S. (2010). Amelioration of sexual adverse effects in the early breast cancer patient. Journal of Cancer Survivorship, 4(3), 247-255. https://doi.org/10.1007/s11764-010-0130-1

Melisko, M. E., Goldman, M. E., Hwang, J., De Luca, A., Fang, S., Esserman, L. J., . . Rugo, H. S. (2017). Vaginal testosterone cream vs estradiol vaginal ring for vaginal dryness or decreased libido in women receiving aromatase inhibitors for early-stage breast cancer: A 
randomized clinical trial. The Journal of the American Medical Association Oncology, 3(3), 313-319. http://doi.org/10.1001/jamaoncol.2016.3904

Moral, E., Delgado, J. L., Carmona, F., Caballero, B., Guillán, C., González, P. M., . . for the writing group of GENISSE study. (2018). Genitourinary syndrome of menopause. Prevalence and quality of life in Spanish postmenopausal women. The GENISSE study. Climacteric, 21(2), 167-173. https://doi.org/10.1080/13697137.2017.1421921

Moyneur, E., Dea, K., Derogatis, L. R., Vekeman, F., Dury, A. Y., \& Labrie, F. (2020). Prevalence of depression and anxiety in women newly diagnosed with vulvovaginal atrophy and dyspareunia. Menopause, 27(2), 134-142. https://doi.org/10.1097/GME.0000000000001450

Nappi, R. E., Kingsberg, S., Maamari, R., \& Simon, J. (2013). The CLOSER (CLarifying Vaginal Atrophy’s Impact On SEx and Relationships) Survey: Implications of vaginal discomfort in postmenopausal women and in male partners. Women's Sexual Health, 10(9), 2232-2241. https://doi.org/10.1111/jsm.12235

Nappi, R. E., \& Kokot-Kierepa, M. (2010). Women's voices in the menopause: Results from an international survey on vaginal atrophy. Maturitas, 67(3), 233-238. $\underline{\text { http://doi.org/10.1016/j.maturitas.2010.08.001 }}$

Nappi, R. E., \& Kokot-Kierepa, M. (2012). Vaginal health: Insights, views \& attitudes (VIVA) results from an international survey. Climacteric, 15(1), 36-44. https://doi.org/10.3109/13697137.2011.647840

Parish, S. J., Nappi, R. E., Krychman, M. L., Kellogg-Spadt, S., Simon, J. A., Goldstein, J. A., \& Kingsberg, S. A. (2013). Impact of vulvovaginal health on postmenopausal women: A 
review of surveys on symptoms of vulvovaginal atrophy. International Journal of Women's Health, 5, 437-447. https://doi.org/10.2147/IJWH.S44579

Pavlović, R. T., Janković, S. M., Milovanović, J. R., Stefanović, S. M., Folić, M. M., Milovanović, O. Z., . . Milosavljević, M. N. (2019). The safety of local hormonal treatment for vulvovaginal atrophy in women with estrogen receptor-positive breast cancer who are on adjuvant aromatase inhibitor therapy: Meta-analysis. Clinical Breast Cancer, 19(6), e731-e740. https://doi.org/10.1016/j.clbc.2019.07.007

Portman, D. J., Gass, M. L. S., \& on behalf of the Vulvovaginal Atrophy Terminology Consensus Conference Panel. (2014). Genitourinary syndrome of menopause: New terminology for vulvovaginal atrophy from the International Society for the Study of Women's Sexual Health and The North American Menopause Society. Menopause, 21(10), 1063-1068. https://doi.org/10.1097/GME.0000000000000329

Rosen, R., Brown, C., Heiman, J., Leiblum, S., Meston, C., Shabsigh, R., . . D'Agostino, R., Jr. (2000). The Female Sexual Function Index (FSFI): A multidimensional self-report instrument for the assessment of female sexual function. Journal of Sex \& Marital Therapy, 26(2), 191-208. https://doi.org/10.1080/009262300278597

Shi, Q., Smith, T. G., Michonski, J. D., Stein, K. D., Kaw, C., \& Cleeland, C. S. (2011). Symptom burden in cancer survivors 1 year after diagnosis: A report from the american cancer society's studies of cancer survivors. Cancer, 117, 2779-2790. https://dio.org/10.1002/cncr.26146

Shifren, J. L., Zincavage, R., Cho, E. L., Magnavita, A., Portman, D. J., Krychman, M. L., .. . Rosen, R. C. (2019). Women's experience of vulvovaginal symptoms associated with 
menopause. Menopause, 26(4), 341-349.

https://doi.org/10.1097/GME.0000000000001275

Sousa, M. S., Peate, M., Jarvis, S., Hickey, M., \& Friedlander, M. (2017). A clinical guide to the management of genitourinary symptoms in breast cancer survivors on endocrine therapy. Therapeutic Advances in Medical Oncology, 9(4), 269-285.

https://doi.org/10.1177/1758834016687260

Sousa, M. S., Peate, M., Lewis, C., Jarvis, S., Willis, A., Hickey, M., \& Friedlander, M. (2018). Exploring knowledge, attitudes and experience of genitourinary symptoms in women with early breast cancer on adjuvant endocrine therapy. European Journal of Cancer Care, 27, e12820. https://doi.org/10.1111/ecc.12820

Su, H. I., Stark, S., Kwan, B., Boles, S., Chingos, D., Ehren, J., . . Natarajan, L. (2020). Efficacy of a web-based women's health survivorship care plan for young breast cancer survivors: A randomized controlled trial. Breast Cancer Research \& Treatment, 176(3), 579-589. http://doi.org/10.1007/s10549-019-05260-6

Sussman, T. A., Kruse, M. L., Thacker, H. L., \& Abraham, J. (2019). Managing genitourinary syndrome of menopause in breast cancer survivors receiving endocrine therapy. Journal of Oncology Practice, 15(7), 363-370. https://doi.org/10.1200/JOP.18.00710

The North American Menopause Society. (2020). NAMS Position Statement: the 2020 genitourinary syndrome of menopause position statement of The North American Menopause Society. Menopause, 27(9), 976-992. http://doi.org/10.1097/GME.0000000000001609

Vincent, A. J. (2015). Management of menopause in women with breast cancer. Climacteric, 18(5), 690-701. https://doi.org/10.3109/13697137.2014.996749 


\section{Table 1}

Demographic and Clinical Variables by Status of Presence/Absence of Genitourinary Symptoms in Breast Cancer Survivors $(N=1,085)$

\section{At least one genitourinary symptom}

\begin{tabular}{ccc}
\hline Yes & No & Pvalue $^{a}$ \\
$n=365$ & $n=720$
\end{tabular}

\section{Demographic variables}

Current age (mean $\pm \mathrm{SD})$

$$
54.8 \pm 11.6
$$

$58.0 \pm 11.5$

$<.001 * *$

Current marital status, No. (\%)

Married/committed relationship

$287(79.3)$

$518(73.3)$

Divorced

$26(7.2)$

$52(7.4)$

Widowed

25 (6.9)

$74(10.5)$

Single

$24(6.6)$

Highest level of education, No. (\%)

4-year college and higher

135 (37.3)

$279(39.5)$

.755

2-year college

130 (35.9)

$240(33.9)$

High school and lower

97 (26.8)

188 (26.6)

Hispanic / Latina, ${ }^{\mathrm{b}}$ No. (\%)

$10(2.7)$

$13(1.8)$

.313

Race, No. (\%)

White

$330(90.4)$

$672(93.3)$

.087

Minority race ${ }^{\mathrm{c}}$

35 (9.6)

48 (6.7)

Income, No. (\%)

Less than $\$ 30,000$

$66(18.5)$

$119(17.2)$

.748

$\$ 30,001-\$ 100,000$

206 (57.9)

417 (60.3)

More than $\$ 100,000$

84 (23.6)

$156(22.5)$ 
BMI (self-reported weight), No. (\%)

Underweight and normal

Overweight

Obese

\section{Clinical variables}

Age at first menses (mean \pm SD)

Years post-breast cancer diagnosis (mean \pm

$\mathrm{SD})$

Number of non-breast cancer comorbidities

$($ mean $\pm \mathrm{SD})$

Current menopausal status, No. (\%)

Premenopausal

Perimenopausal

Naturally postmenopausal

Surgically postmenopausal

Artificially postmenopausal

Taking treatment for menopausal symptoms, ${ }^{1}$

No. $(\%)$

Currently taking SERM or AI, ${ }^{1}$ No. (\%)
$128(35.4)$

$115(31.8)$

$119(32.9)$
$241(33.6)$

.718

$245(34.2)$

$231(32.2)$
$12.6 \pm 1.5 \quad 12.6 \pm 1.5$

.486

$6.0 \pm 1.5$

$5.9 \pm 1.5$

.668

$1.9 \pm 1.7$

$.024 *$

$36(10.1)$

$37(5.3)$

$<.001 * *$

$42(11.8)$

$51(7.3)$

$97(27.2)$

$257(36.7)$

$110(30.9)$

$206(29.4)$

$71(19.9)$

$150(21.4)$

$157(43)$

$213(29.6)$

$<.001 * *$

${ }^{a}$ Comparison of breast cancer survivors with and without genitourinary symptoms, two-sided $t$ tests for continuous variables and Pearson chi-square test for categorical variables. ${ }^{\mathrm{b}} \mathrm{n}(\%)$ reporting yes by genitourinary symptom. ${ }^{c}$ Minority race $(n=83)$ includes Black or African American $(n=15$ with at least one genitourinary symptom; $\mathrm{n}=25$ with no symptoms), Native Hawaiian or other Pacific Islander ( $\mathrm{n}=0$ with at least one symptom; $\mathrm{n}=0$ with no symptoms), Asian ( $\mathrm{n}=5$ with at least one symptom; $\mathrm{n}$ 
$=5$ with no symptoms), American Indian or Alaskan Native $(n=0$ with at least one symptom; $n=1$ with no symptoms), or Other ( $\mathrm{n}=15$ with at least one symptom; $\mathrm{n}=17$ with no symptoms). $* \mathrm{p}<.05 ; * \mathrm{p}<.001$

SERM, selective estrogen receptor modulator; AI, aromatase inhibitor. 


\section{Table 2}

Prevalence of Genitourinary Symptoms among Breast Cancer Survivors $(N=1,085)$

\begin{tabular}{lcc}
\hline Genitourinary symptom & N & \% \\
\hline Vaginal/vulvar irritation & 163 & 15.0 \\
Pelvic discomfort & 162 & 14.9 \\
Problem with urinary control & 99 & 9.1 \\
Vaginal infection & 46 & 4.2 \\
Vaginal bleeding & 44 & 4.1 \\
\hline Reported at least 1 symptom & 365 & 33.6 \\
Reported 2 or more symptoms & 110 & 10.1 \\
\hline
\end{tabular}




\section{Table 3}

Results of Multivariable Logistic Regression: Correlates of Breast Cancer Survivors Reporting at least One Genitourinary Symptom $(N=1,042)^{a}$

\begin{tabular}{|c|c|c|c|c|c|}
\hline Correlate & B & $\begin{array}{c}\text { Standard } \\
\text { Error }\end{array}$ & $\begin{array}{c}\text { Adjusted } \\
\text { Odds Ratio }\end{array}$ & $95 \% \mathrm{CI}$ & $P$ value \\
\hline Current age & -0.02 & 0.01 & 0.98 & {$[0.96-0.99]$} & $.010 *$ \\
\hline \multicolumn{6}{|l|}{ Marital status (ref: married) } \\
\hline Divorced & -0.15 & 0.27 & 0.87 & {$[0.52-1.46]$} & .585 \\
\hline Widowed & -0.34 & 0.27 & 0.71 & {$[0.42-1.20]$} & .203 \\
\hline Single & -0.34 & 0.27 & 0.72 & {$[0.42-1.21]$} & .210 \\
\hline Minority race (ref: white) & 0.44 & 0.26 & 1.55 & {$[0.93-2.56]$} & .091 \\
\hline $\begin{array}{l}\text { Number of non-breast cancer } \\
\text { comorbidities }\end{array}$ & 0.17 & 0.04 & 1.19 & {$[1.09-1.29]$} & $<.001 * *$ \\
\hline $\begin{array}{l}\text { Menopausal status (ref: } \\
\text { premenopausal) }\end{array}$ & & & & & \\
\hline Perimenopausal & -0.14 & 0.32 & 0.87 & {$[0.46-1.63]$} & .658 \\
\hline Naturally postmenopausal & -0.60 & 0.34 & 0.55 & {$[0.28-1.08]$} & .081 \\
\hline $\begin{array}{l}\text { Surgically } \\
\text { postmenopausal }\end{array}$ & -0.52 & 0.30 & 0.59 & {$[0.33-1.08]$} & .085 \\
\hline $\begin{array}{l}\text { Artificially } \\
\text { postmenopausal }\end{array}$ & -0.69 & 0.29 & 0.50 & {$[0.28-0.89]$} & $.018^{*}$ \\
\hline Taking treatment for & & & & & \\
\hline $\begin{array}{l}\text { menopausal symptoms (ref: } \\
\text { no) }\end{array}$ & 0.55 & 0.14 & 1.73 & {$[1.31-2.30]$} & $<.001 * *$ \\
\hline Summary statistics & & & $\chi^{2}$ & $\mathrm{df}$ & $P$ value \\
\hline
\end{tabular}




\begin{tabular}{lccc}
\hline Likelihood ratio test & 64.08 & 11 & $<.001$ \\
Hosmer and Lemeshow & 9.62 & 8 & .293
\end{tabular}

Pseudo $\mathrm{R}^{2}=.08$

${ }^{a}$ Women with complete data for all variables $(n=1,042)$ were included in the multivariable logistic regression model. CI, confidence interval.

$* \mathrm{p}<.05 ; * \mathrm{p}<.001$ 


\section{Table 4}

Sexual Functioning by Status of Genitourinary Symptoms

\begin{tabular}{|c|c|c|c|c|}
\hline Symptom & & $\begin{array}{c}\text { Sexual functioning } \\
\text { total } \\
\text { Mean (SD) } \\
(n=808)\end{array}$ & $\begin{array}{l}\text { Sexual enjoyment } \\
\begin{array}{l}\text { Mean (SD) } \\
(\mathrm{n}=811)\end{array}\end{array}$ & $\begin{array}{l}\text { Sexual difficulty } \\
\text { Mean (SD) } \\
(n=804)\end{array}$ \\
\hline $\begin{array}{c}\text { Vaginal/vulvar } \\
\text { irritation }\end{array}$ & $\begin{array}{c}\text { Yes } \\
\text { No } \\
P \text { value }\end{array}$ & $\begin{array}{l}17.8(5.6) \\
20.3(5.5) \\
<.001 * * *\end{array}$ & $\begin{array}{c}11.2(3.2) \\
12.0(3.1) \\
.004 * *\end{array}$ & $\begin{array}{l}11.4(3.0) \\
9.7(3.2) \\
<.001 * * *\end{array}$ \\
\hline $\begin{array}{c}\text { Pelvic } \\
\text { discomfort }\end{array}$ & $\begin{array}{c}\text { Yes } \\
\text { No } \\
P \text { value }\end{array}$ & $\begin{array}{c}18.9(5.6) \\
20.0(5.6) \\
.031 *\end{array}$ & $\begin{array}{c}11.2(3.2) \\
12.0(3.1) \\
.004 * *\end{array}$ & $\begin{array}{c}10.3(3.1) \\
10.0(3.3) \\
.351\end{array}$ \\
\hline $\begin{array}{l}\text { Problem with } \\
\text { urinary control }\end{array}$ & $\begin{array}{c}\text { Yes } \\
\text { No } \\
P \text { value }\end{array}$ & $\begin{array}{c}18.0(5.2) \\
20.0(5.6) \\
.008 * *\end{array}$ & $\begin{array}{c}11.0(2.9) \\
11.9(3.2) \\
.019 *\end{array}$ & $\begin{array}{c}11.2(2.9) \\
9.9(3.3) \\
.005^{* *}\end{array}$ \\
\hline Vaginal infection & $\begin{array}{c}\text { Yes } \\
\text { No } \\
P \text { value }\end{array}$ & $\begin{array}{c}17.9(5.1) \\
20.0(5.6) \\
.029 *\end{array}$ & $\begin{array}{c}11.0(2.9) \\
11.9(3.2) \\
.096\end{array}$ & $\begin{array}{c}11.2(3.1) \\
10.0(3.2) \\
.029 *\end{array}$ \\
\hline Vaginal bleeding & $\begin{array}{c}\text { Yes } \\
\text { No } \\
P \text { value }\end{array}$ & $\begin{array}{c}20.0(5.3) \\
19.9(5.6) \\
.855\end{array}$ & $\begin{array}{c}11.3(3.2) \\
11.9(3.1) \\
.249\end{array}$ & $\begin{array}{c}9.3(3.4) \\
10.1(3.2) \\
.144\end{array}$ \\
\hline $\begin{array}{c}\text { Reported at least } \\
1 \text { symptom }\end{array}$ & $\begin{array}{c}\text { Yes } \\
\text { No } \\
P \text { value }\end{array}$ & $\begin{array}{l}18.9(5.5) \\
20.4(5.6) \\
<.001 * * *\end{array}$ & $\begin{array}{l}11.4(3.2) \\
12.2(3.1) \\
<.001 * * *\end{array}$ & $\begin{array}{c}10.5(3.2) \\
9.7(3.3) \\
.001 * *\end{array}$ \\
\hline & Yes & $17.6(5.2)$ & $10.7(2.9)$ & $11.2(3.1)$ \\
\hline
\end{tabular}




\begin{tabular}{|c|c|ccc|} 
Reported 2 or & No & $20.2(5.6)$ & $12.0(3.1)$ & $9.9(3.2)$ \\
more symptoms & P value & $<.001^{* * *}$ & $<.001^{* * * *}$ & $<.001^{* * *}$ \\
\hline
\end{tabular}

Note. t-tests used to compare sexual functioning, sexual enjoyment, and sexual difficulty between presence and absence of genitourinary symptoms.

$* \mathrm{p}<.05 ; * * \mathrm{p}<.01 ; * * * \mathrm{p}<.001$ 


\section{Figure 1}

Situation Specific Model of Genitourinary Symptoms in Breast Cancer Survivors

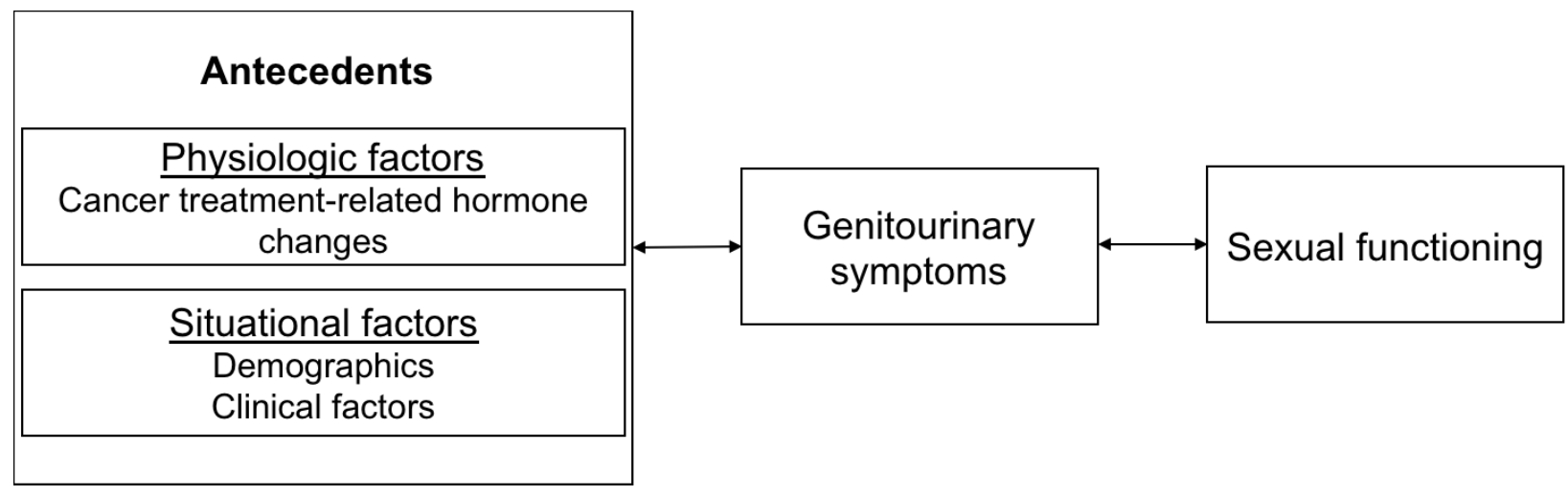

Source: This model was based on Lenz, E. R., \& Pugh, L. C. (2003). The theory of unpleasant symptoms. In M. J. Smith \& P. R. Liehr (Eds.), Middle range theory for nursing (pp. 165-195). New York: Springer; Lenz, E. R., Pugh, L. C., Milligan, R. A., Gift, A., \& Suppe, F. (1997). The middle-range theory of unpleasant symptoms: An update. Advances in Nursing Science, 19(3), 14-27. https://doi.org/10.1097/00012272-199703000-00003 